\title{
Psicoterapia analítico-comportamental em grupo
}

\author{
José Kleidir de Castro Feitosa ${ }^{1}$, Ana Nery de Castro Feitosa ${ }^{2}$, \\ Adriano Monteiro de Oliveira ${ }^{3}$
}

\begin{abstract}
Resumo: A necessidade de um procedimento psicoterapêutico em grupo cresce à medida que aumenta também a demanda para atendimentos psicoterapêuticos. O objetivo deste trabalho é explanar sobre aspectos da psicoterapia de grupo sob a ótica da análise do comportamento. Observa-se que o trabalho em grupo pode atingir uma parte da sociedade que não tem acesso ao serviço individual.
\end{abstract}

Palavras-chave: Psicoterapia de grupo, análise do comportamento, psicologia.

\section{Behavior-analytic psychotherapy group}

\begin{abstract}
The need for a psychotherapeutic procedure group grows as also increases the demand for psychotherapeutic care. The objective of this work is to explain about aspects of group psychotherapy from the perspective of behavior analysis. It is observed that the group work can reach a part of society that does not have access to the individual service.
\end{abstract}

Keywords: psychotherapy group, behavior analysis, psychology.

\section{Introdução}

Sabe-se que, para a análise do comportamento o ambiente tem extrema importância na modelagem e manutenção de padrões de comportamento. Sabe-se também que é crescente os registros de eficácia da análise aplicada do comportamento. Ao tratarmos de análise do comportamento estamos falando basicamente de análise e modificação de contingências, onde por contingências entende-se a relação de causa e efeito entre eventos.

Skinner (1967) diz que se o indivíduo tiver conhecimento das contingências que controlam o seu comportamento será muito mais eficaz no controle de sua vida cotidiana.

\footnotetext{
${ }^{1}$ Psicólogo e Especialista em Saúde Mental pela Universidade Estadual do Ceará - UECE. E-mail: kleidirfeitosa@ hotmail.com;

2 Terapeuta Ocupacional, Mestre em Gerontología Social pela Universidad de León. Mestranda em Gestão em Saúde, pela Universidade Estadual do Ceará - UECE. E-mail: ananfeitosa@yahoo.com.br;

${ }^{3}$ Enfermeiro, Especialista em Gerontologia e Saúde Mental, Mestrando em Teologia com habilitação em Dimensões do Cuidado e Práticas Sociais pela Faculdade EST.

Autor correspondente: kleidirfeitosa@hotmail.com.
} 
Assim torna-se o objetivo da análise do comportamento, em clínica, analisar e modificar contingências e como resultado a modificação do comportamento, isso é o que chamamos de terapia comportamental.

A terapia, ainda segundo a visão behaviorista de Skinner, funciona como uma agência controladora, como a religião e governo, porém não tão organizada como ambas, mas que constitui uma profissão que lida com comportamentos operantes, mas não se desfaz da emoção ou sentimentos, já que estes também são inerentes ao homem.

Existe ainda outro aspecto muito importante para lidar na terapia comportamental, são as regras, ou crenças (Descrições verbais antecedentes). Skinner (1967) fala sobre a diferença entre comportamentos controlados pelas contingências e comportamentos controlados por regras. O primeiro tem suas respostas modeladas pelas consequências especificadas nas contingências, já o segundo tem suas respostas caracterizadas como operantes discriminativos e são controladas pelo reforçamento do comportamento de seguir regras.

Quando o indivíduo aprende a suas próprias regras (descrições verbais das contingências onde está inserido) fica sob controle mais adequado da correspondência dizer fazer, podendo assim emitir comportamentos mais adequados pois poderá reagir eficazmente quando o controle por contingências estiver enfraquecido. No caso da terapia de grupo os clientes fazem parte das contingências, o terapeuta deve ficar atento para que esta correspondência ocorra, evitando possíveis respostas de esquiva ou de agressividade entre os clientes.

Como a análise do comportamento é embasada em um princípio de aprendizagem, o terapeuta pode fazer uso disso ensinando a seus clientes sobre análise do comportamento, sobre relações entre os comportamentos e as consequências, a descrever contingências e construir suas próprias regras (auto-regras). Ensinar análise funcional ao cliente é um dos melhores recursos terapêuticos.

Um outro recurso presente na psicoterapia de grupo é o que chamamos de modelo, onde uns clientes servem de modelo para outros e o terapeuta serve de modelo comportamental para os clientes. Em psicoterapia de grupo, além dos reforçadores descritos 
por cada cliente (individualmente) podemos trabalhar com o próprio reforço social, onde o grupo emite um "feedback" para o cliente que relatou algo.

Diante do exposto, este artigo tem por objetivo explanar sobre aspectos da psicoterapia de grupo sob a ótica da análise do comportamento.

\section{Qual o objetivo do grupo?}

O grupo será para obtenção de dados para pesquisa? Atendimento em consultório ou em instituição? Se instituição é uma clínica - escola , hospital psiquiátrico, posto de saúde ou empresa? A resposta a esta questão determinará todas as características do grupo. Uma das características da Análise do Comportamento é a utilização de uma definição objetiva dos problemas para fins da análise funcional. A definição e descrição operacional dos objetivos são indispensáveis para o planejamento das intervenções e também para avaliação dos resultados.

\section{Quantos clientes participarão do grupo?}

Não existe uma norma ou recomendação que especifique o número ideal de participantes. Esta é uma das decisões que o terapeuta deverá tomar, considerando seus objetivos e as demais características do grupo. Grupos maiores (mais de 8 participantes) demandam um maior treino terapêutico, embora sejam muito úteis nas instituições (hospitais, empresas) nas quais a demanda por atendimento costuma ser maior. Terapeutas menos experientes provavelmente se beneficiam se trabalharem com grupos menores ( 4 a 5 pessoas) e, portanto, com menos diferenças individuais em termos de problemas e de história de aprendizagem. Grupos menores, por outro lado, podem trazer outro tipo de dificuldade: se um participante faltar, o que realmente pode ocorrer, a interação na sessão pode ficar pequena ou aversiva para os membros do grupo. 
Id on Line Revista Multidisciplinar e de Psicologia

Id on Line Multidisciplinary Journal and Psycology

\section{Quantos terapeutas?}

Ter um co-terapeuta tem se mostrado extremamente produtivo, na situação de grupo fica difícil para um único terapeuta observar e discriminar os comportamentos verbais e não verbais de todos os clientes. Assim, enquanto um terapeuta está interagindo com um cliente o outro terapeuta observa os demais e se preciso interfere, mudando o foco da análise ou completando a verbalização. Deve-se, entretanto, tomar cuidado para que um terapeuta não fique constantemente completando a afirmação do outro o que pode reduzir a oportunidade de participação dos membros do grupo.

\section{O grupo será homogêneo ou heterogêneo?}

O grupo será composto por pessoas semelhantes em termos de idade, tipo de problema, e sexo dos participantes ou não? Esta decisão depende dos objetivos do trabalho, isto é, grupos homogêneos são mais adequados para realizar uma pesquisa, para discutir uma temática específica (por exemplo, grupo de mulheres para discutir sexualidade), ou grupos heterogêneos com temas mais genéricos como habilidades sociais, problemas de relacionamento, ansiedade etc.

\section{O grupo será aberto ou fechado?}

Novos membros podem passar a participar do grupo depois de seu início ou não? Se a opção for pelo grupo fechado cada pessoa assume o compromisso de participar por algum tempo específico (alguns meses, por exemplo). Quando se trabalha com grupo aberto o terapeuta deve se lembrar que sempre que um novo membro for acrescido deverá ser feito um resumo do que já ocorreu no grupo e uma retomada das regras e condições do grupo. Nas instituições como hospitais e centros de atendimento à saúde este tipo de grupo é mais frequente nas enfermarias. No entanto, nos ambulatórios é possível a realização de grupos 
fechados, temáticos, e as vezes com número pré - determinado de sessões tanto para pesquisa quanto para atendimento aos pacientes da instituição.

\section{Local, duração, frequência e valor das sessões}

Não existe uma regra para isso, mas o modelo de encontros semanais com duração de 2 goras é bastante usado. É difícil estabelecer o preço da sessão de grupo. Para atender seis ou mais pessoas é preciso uma sala de tamanho grande. Além disso, trabalham dois terapeutas e um observador e o planejamento e discussão da sessão demanda várias horas além das utilizadas durante o atendimento. Muitos profissionais costumam cobrar $50 \%$ do valor individual.

\section{Psicoterapia de grupo sob a ótica da análise do comportamento}

\section{O início}

Segundo os relatos de experiências de Delitti (2008) o ideal seria iniciar o processo com um ou dois encontros individuais antes dos encontros em grupo. Esses encontros iniciais servem para coletar informações como as expectativas do cliente em relação ao grupo, comportamentos que considera problema (e quando possível as contingências de aquisição e manutenção dos mesmos), além disso é papel do terapeuta procurar estabelecer-se como audiência não punitiva e explicar os processos e princípios básicos da psicoterapia de grupo.

Após a(s) primeira(s) entrevista(s) individuais pode-se dar início ao processo de psicoterapia de grupo, atentando-se para algumas etapas. Na primeira sessão os terapeutas criam condições para os participantes se conhecerem, se apresentando, e exporem suas expectativas iniciais. Um outro início possível seria pedir para que um membro se apresente para o colega do lado falando um pouco de si como características pessoais e interesses, e após essa interação (que dura em média de 3 a 5 minutos) pedir que um apresente o outro. 
Este tipo de apresentação, além de facilitar a interação, facilita ainda a emissão de operantes verbais em clientes com mais dificuldades.

Ainda segundo Delitti (2008) no início do processo, ou seja, nas primeiras 3 ou 4 sessões, os dois objetivos principais são reforçar a classe de respostas de "ser cliente" onde envolvem comportamentos de chegar na hora (pontualidade), não faltar (assiduidade), cooperação no grupo e também retomar a coleta e iniciar a análise dos dados obtidos nas entrevistas individuais. E indispensável o estabelecimento de controle positivo entre os membros, isto é, o terapeuta deverá reforçar os comportamentos verbais do tipo tato e o de reforçamento recíproco entre os membros. E também importante que o terapeuta esteja atento para identificar e indicar aos clientes os comportamentos e contingências de vida semelhantes ou que alguma forma favoreçam a interação e a aprendizagem de uns pelas contingências de aprendizagem dos outros.

O terapeuta deve também saber lidar com a coesão do grupo pois é uma das variáveis indispensáveis no trabalho grupal. Delitti (2008) considera a coesão como uma razão entre a taxa de reforço versus a de punição liberada pelo grupo, ou seja, grupos mais coesos são aqueles em que existem mais comportamentos mantidos por controle positivo do que por controle aversivo.

A coesão é o resultado de todas as forças que atuam sobre todos os membros do grupo, de maneira que permaneçam no grupo,ou de forma mais simples a atração de um grupo por seus membros.Os membros de um grupo coeso sentem afeto, conforto e um sentido de pertinência no grupo. Eles valorizam o grupo e sentem que são valorizados, aceitos e amparados pelos outros membros. (YALOM apud DELITTI, 2008).

No contexto grupal, a coesão faz com que cada cliente se estabeleça como parte de um ambiente não punitivo e assim favorece a emissão de padrões de comportamento que são punidos em situação natural. A coesão, no grupo, coloca-se no lugar da relação terapêutica no trabalho individual.

Em psicoterapia de grupo podemos falar que o terapeuta fica sob controle dos comportamentos dos clientes enquanto estes ficam sob controle das contingências liberadas pelo terapeuta e pelo grupo $\mathrm{Na}$ situação de grupo cada individuo pode desempenhar o papel de modelo e liberar reforço social para aprendizagem de novos padrões de comportamento o 
que pode facilitar a generalização para a situação natural. Quando os clientes identificam os efeitos de seus comportamentos sobre o comportamento do terapeuta e dos outros membros do grupo em uma situação de controle positivo, é maior a probabilidade de discriminação de quais comportamentos serão reforçados se emitidos na situação natural.

\section{Avaliação inicial}

Muitos clientes iniciam o processo relatando suas queixas, ou o porque de buscar uma psicoterapia. A primeira tarefa do terapeuta é analisar as queixas descrevendo-as em termos de comportamentos específicos passíveis de observação (direta ou indireta) e de mudança. Com a descrição das contingências é possível identificar as consequências desses comportamentos para o indivíduo e/ou para as pessoas com quem convive. Tratando-se de queixas em análise do comportamento podemos falar em excessos e déficits comportamentais. Os excessos comportamentais referem-se àqueles comportamentos que são emitidos em frequiência, duração ou intensidade muito alta ou em situações inadequadas. Déficits comportamentais são os padrões de comportamento que não são emitidos na frequência, intensidade ou duração necessária, da forma apropriada ou em situações inadequadas para trazer reforçamento positivo ou evitar punições (reforçamento negativo).

Na clínica individual a mensuração e avaliação têm os objetivos de identificar os comportamentos-alvo e as circunstâncias que mantêm tais comportamentos; auxiliar na seleção de uma intervenção apropriada; fornecer meios de monitoramento dos progressos do tratamento; auxiliar na avaliação da eficácia de uma intervenção.

No contexto grupal existem algumas formas de fazer essa mensuração como: os clientes podem aprender a observar e, se necessário, registras seus próprios comportamentos respondendo a inventários já padronizados; ou fazendo registro de certos comportamentos emitidos em situações específicas. 
Id on Line Revista Multidisciplinar e de Psicologia

Id on Line Multidisciplinary Journal and Psycology

\section{O desenvolvimento do grupo}

Deve-se levar em consideração que apenas uma pequena parte da vida do cliente se passa na terapia e que esse pouco tempo (duração da sessão) é o momento que o terapeuta se utiliza para observar o comportamento do cliente e também se inserir nas contingências. Uma das funções do psicoterapeuta embasado na teoria comportamental será de emitir situações em que o cliente entre em contato e identifique as classes de contingências de reforço em seu histórico que o fizeram emitir determinada resposta que ele traz como gerador de sofrimento e também identificar o que (que contingências) mantem esse padrão hoje em seu repertório, ou seja, ele deve ajudar o cliente a identificar como adquiriu o comportamento e porque ainda o emite.

Existe também dois fenômenos descritos pelas abordagens psicanalíticas como "transferência" e "contratransferência", que em análise do comportamento podemos falar em discriminação e generalização por parte do cliente e também do terapeuta. Tudo que o cliente faz na sessão são comportamentos que foram aprendidos e ocorrem devido à similaridade funcional entre estímulos presentes na sessão e na situação de aprendizagem. Por exemplo, quando se sente irritado com um comportamento do cliente o terapeuta deve se perguntar: será que este comportamento do cliente é uma amostra de seu comportamento na situação natural e dos respondentes que evoca nas outras pessoas ou eu estou irritado porque estou cansado? Ao fazer este auto - questionamento o terapeuta estará procurando identificar se seus eventos privados foram evocados pelo comportamento do cliente ou por contingências de sua história pessoal. Na sessão de grupo esta reflexão é facilitada, pois pode - se fazer a validação consensual, isto é, perguntar aos outros membros do grupo e ao co-terapeuta como se sentiram naquela situação. A partir dos relatos dos outros clientes pode-se verificar se eles identificam os mesmos respondentes e, portanto, não foi uma resposta evocada/eliciadas apenas por contingências da história de vida do terapeuta. (DELITTI, 2008).

A análise do comportamento se utiliza de vários procedimentos como reforçamento, extinção, treino discriminativo, etc. Porém um método bastante usado é o processo de modelação e ensaio comportamental. 
Id on Line Revista Multidisciplinar e de Psicologia

Id on Line Multidisciplinary Journal and Psycology

\section{Modelação e ensaio comportamental}

$\mathrm{Na}$ terapia grupal a modelação, ou aprendizagem por observação, é um dos instrumentos mais importantes, pois o terapeuta serve de modelo para comportamentos no grupo e, por sua vez, o s membros dos grupos servem de modelo uns para os outros.

Segundo Bandura $(1969,1971)$ a modelação pode ter três efeitos sobre os clientes: primeiro os observadores podem adquirir novos padrões de comportamento; além disso, a modelação também pode fortalecer ou inibir respostas que já existem no repertório do observador, e estão reprimidas por contingências aversivas; e por último a modelação pode facilitar respostas que já existem no repertório do indivíduo, mas são emitidas em baixa frequência.

O autor relata que a imitação é essencial para a existência de uma cultura, pois possibilita a reprodução e continuidade de valores economizando tempo na aprendizagem e garantindo a aquisição de comportamentos adaptativos mais funcionais para a sobrevivência da espécie. Os pais são os primeiros modelos a serem seguidos por seus filhos e servem de modelo para muitos comportamentos diferentes. Esses comportamentos podem ser mais aceitos socialmente, como por exemplo, o comportamento amoroso, ou ser menos aceitos, como a imitação de comportamentos violentos por crianças que têm pais agressivos. Existem ainda alguns fatores que podem facilitar a aprendizagem por observação como a habilidade do cliente em observar e discriminar traços e comportamentos, características do modelo, similaridades, etc.

Já o ensaio comportamental se caracteriza por simulações de situações reais vividas pelo cliente situações nas quais ele apresenta algum grau de dificuldade e pode ser utilizado para avaliação e para intervenção.

Modelação e o ensaio de comportamento como estratégia de avaliação: Quando o indivíduo representa uma situação que tenha ocorrido em sua vida pode se observar seu comportamento verbal e não verbal, a topografia dos mesmos, tom de voz, gestos, entonação e postura. Esta observação costuma fornecer dados importantes para a análise das contingências. 
Modelação e o ensaio de comportamento como estratégia de Intervenção: são inúmeros os comportamentos que podem ser instalados ou alterados, desde comportamento de observar a si e aos outros, analisar e descrever contingências, habilidades sociais, empatia, comunicação, auto-revelação, enfrentamento, etc. Vale a pena salientar que os primeiros modelos de comportamentos que o terapeuta apresenta para os clientes são os auto - relatos, principalmente aqueles cujo conteúdo mostre empatia e aceitação social, isto é o terapeuta dá modelo de como os clientes podem liberar reforço social. A modelação pode ser facilitada quando, por exemplo, durante um ensaio de comportamento no grupo o terapeuta der uma instrução prévia oral ou escrita em cartões levando os clientes a ficar sob controle dos estímulos relevantes, dizendo, por exemplo: "prestem atenção ao tom de voz e aos gestos do P nesta situação”.

Uma variação de modelação ocorre quando o terapeuta atua como espelho, isto é, emite um comportamento (verbal ou não) similar a um comportamento emitido ou descrito pelo cliente para o grupo observar, reforçar diferencialmente e, se necessário e possível, emitir comportamentos alternativos. Além disso, pode ser feita a troca de papéis: o cliente troca de papel com outro participante da dramatização, seja ele terapeuta ou outro membro do grupo. (DELITTI, 2008)

\section{O término do grupo}

É importante no trabalho em grupo, assim como no trabalho individual, que o terapeuta estabeleça condições para a manutenção e generalização dos comportamentos aprendidos no contexto do grupo para seu ambiente natural, Como afirma Skinner (1989) “[...] entretanto, aquilo que o cliente faz na clínica não é a preocupação básica. O que acontece lá é uma preparação para um mundo que não está sob controle do terapeuta."

Pode-se dizer que o objetivo da psicoterapia também seria fazer com que o cliente leve para o ambiente natural os princípios que aprendeu na terapia, aqui pode-se dizer que o processo é mais fácil na situação em grupo pois no grupo é mais fácil planejar na generalização pela diversidade de modelos e de contingências de reforçamento. $\mathrm{O}$ terapeuta 
solicita e incentiva os clientes a emitirem aqueles comportamentos que são aprendidos e ensaiados no grupo na vida real (DELITTI, 2008).

\section{Conclusões}

$\mathrm{O}$ aspecto pedagógico da análise do comportamento facilita o processo até chegar nos objetivos acima descritos. É comum os terapeutas analítico-comportamentais ensinarem a seus clientes a análise de contingências para que estes cheguem até os antecedentes e mantenedores de seus comportamentos-alvo, cujo trazem sofrimento e são geradores de angústia. A probabilidade de generalização de comportamentos aprendidos no contexto da psicoterapia é aumentada se o cliente aprender os princípios que explicam seus comportamentos.

Em suma o trabalho em grupos apresenta vantagens a nível de reforço, pois a fonte de reforço (no ambiente terapêutico) deixa de ser apenas o psicoterapeuta, nos modelos, que se tornam mais variados pela variedade de históricos e repertórios presentes na sessão, e ainda pelo fato da similaridade entre os repertórios, o que pode ajudar no processo de identificação de comportamentos uns nos outros (modelação).

\section{Referências}

BANDURA, A. (1969). Principles of Behavior Modification. New York: Holt, Rinehart and Winston.

SKINNER,BF.-(1967).Ciência e Comportamento Humano.Ed Universidade de Brasília.

SKINNER, B. F. (1989) Questões recentes na análise comportamental. Merrill Publishing Company.

DELITTI, M. (2008) Terapia analítico comportamental em grupo. Em Terapia analítico comportamental em grupo (liv.). Faculdade de Psicologia da Pontifícia Universidade Católica PUC- S.Paulo. 
Id on Line Revista Multidisciplinar e de Psicoloqia

Id on Line Multidisciplinary Journal and Psycology

\section{Como citar este artigo (Formato ABNT):}

FEITOSA,J.K.C.; FEITOSA, A.N.C.; OLIVEIRA, A.M. Psicoterapia Analítico-comportamental. Id on Line Revista Multidisciplinar e de Psicologia, Set-Out de 2016, vol.10, n.31, Supl 2, p. 202-235. ISSN 1981-1179.

Recebido: 21/09/2016

Aceito: $29 / 09 / 2016$ 